Hydrology and Earth System Sciences, 8(1), 115-118 (2004) C EGU

\title{
The origin of summer monsoon rainfall at New Delhi by deuterium excess
}

\author{
Hongxi Pang ${ }^{1}$, Yuanqing He${ }^{1,2}$, Zhonglin Zhang ${ }^{1}$, Aigang $\mathrm{Lu}^{1}$ and Juan $\mathrm{Gu}^{1}$ \\ ${ }^{1}$ Cold and Arid Regions Environmental and Engineering Research Institute, Chinese Academy of Science, Lanzhou 730000, China \\ ${ }^{2}$ Institute of Tibetan Plateau, Chinese Academy of Science, Beijing 100029, China
}

Email for corresponding author: phx_anu@hotmail.com

\begin{abstract}
The deuterium excess in summer monsoon precipitation, determined from isotopic measurements $\left(\delta^{18} \mathrm{O}\right.$ and $\left.\delta \mathrm{D}\right)$ at New Delhi, has been shown to be correlated, negatively, with relative humidity at the $1000 \mathrm{hPa}$ level over the western Arabian Sea. Furthermore, summer rainfall in north-western India is correlated, positively, with the zonal wind speed at the $1000 \mathrm{hPa}$ level over the western Arabian Sea, while relative humidity is correlated, negatively, with zonal wind speed at the same level. It is concluded that evaporation from the western Arabian Sea is a major source of the summer rainfall at New Delhi.
\end{abstract}

Keywords: deuterium excess, relative humidity, origin of precipitation

\section{Introduction}

The south-west Indian monsoon, a large-scale atmospheric circulation system in southern Asia, prevailing from June to September, contributes some $60-90 \%$ of the annual rainfall in monsoon-controlled regions of India. Accordingly, it is important to study the origin of the moisture and its transportation processes over this region. According to measurements during the International Indian Ocean Expedition (IIOE), Pisharoty (1965) indicated that evaporation from the Arabian Sea is a major contributor to Indian summer monsoon rain. Rao et al. (1981) suggested that nearly $40 \%$ of Arabian Sea evaporation is precipitated locally and the rest is transported to the Indian subcontinent. Furthermore, Murakami et al. (1984) considered that the cross equatorial air-flow from the southern Indian Ocean cannot reach South Asia to form rainfall, so evaporation from the Arabian Sea should be an important source of Indian precipitation. Yet, based on vapour flux studies in the troposphere, Pearce and Mohanty (1984) suggested that Indian summer rain originates mainly in the southern Indian Ocean. Kumar and Schluessel (1988) also considered that $70 \%$ of the moisture for the monsoon rains in India comes from the Southern Hemisphere.
In the present study, $\delta^{18} \mathrm{O}$ and $\delta \mathrm{D}$ precipitation data from the IAEA/WMO station at New Delhi have been analysed and the deuterium excess (d-excess) series from 1961-1996 determined. Also, summer rainfall data in north-western India (Fig. 1) and relative humidity and wind speed at the

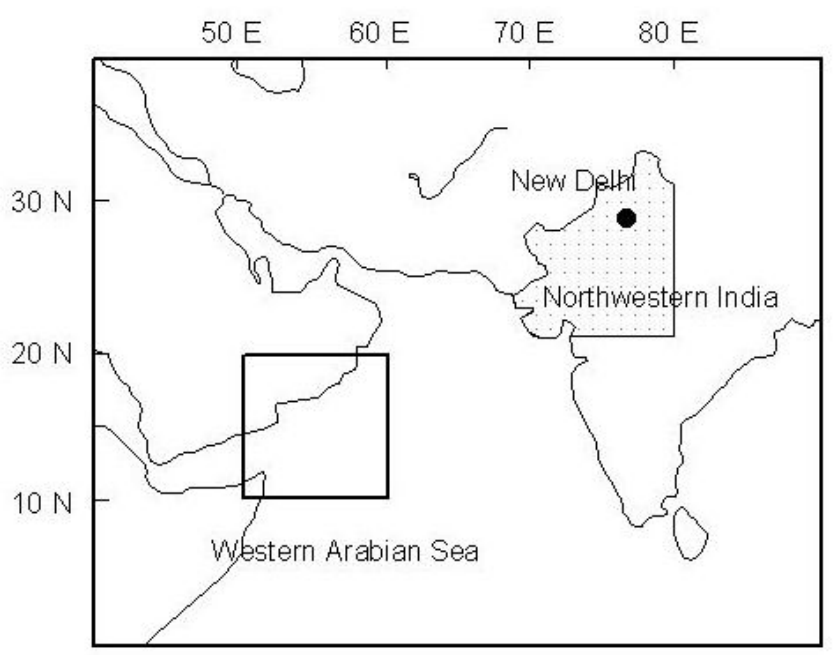

Fig 1. Sketch map of the study area and site location, New Delhi 
$1000 \mathrm{hPa}$ level over the Western Arabian Sea, derived from NCEP/NCAR data, have been included in the analysis, to trace the source of summer monsoon precipitation at New Delhi.

\section{Data and methodology}

The $\delta^{18} \mathrm{O}$ and $\delta \mathrm{D}$ data applied in the paper, were retrieved from GNIP (Global Network for Isotopes in Precipitation), accessible at: http://isohis.iaea.org; the re-analysis data of NCEP/NCAR zonal wind speed and relative humidity are available at http://www.cdc.noaa.gov/cdc/reanalysis/ reanalysis.shtml; and the summer monsoon rainfall of the northwestern India refers to Sontakke and Nityanand Singh (1996).

Craig (1961) defined the correlation between $\delta^{\prime} \mathrm{D}$ and $\delta^{18} \mathrm{O}$ in atmospheric precipitation as the meteoric water line (MWL), which can be expressed as

$$
\delta \mathrm{D}=8 \delta^{18} \mathrm{O}+10 \text {. }
$$

Because of rapid evaporation in precipitation source areas, the fractionation of oxygen and hydrogen does not normally occur under equilibrium conditions so there is a difference between $\delta \mathrm{D}$ and $\delta^{18} \mathrm{O}$. Dansgaard (1964) defined this parameter as d-excess, which is both an indicator of nonequilibrium conditions and an index of evaporation rate, formulated as

$$
\text { d-excess }=\delta \mathrm{D}-8 \delta^{18} \mathrm{O} \text {. }
$$

The d-excess in precipitation depends on the relative humidity in the precipitation source area (Merlivat and Jouzel, 1979; Jouzel and Merlivat, 1984). Lower relative humidities cause higher d-excess values in precipitation and vice versa. Therefore, the moisture source for the monsoon rain of New Delhi can be traced by d-excess based on the correlation between the d-excess and the relative humidity over the potential source of the water vapour.

To smooth other factors controlling d-excess variation, (wind speed, sea surface temperature over the source area and the re-evaporation of raindrops), the mean d-excess value from June to September was used in the analysis. Compared with other IAEA/WMO stations in the monsoon regions, at New Delhi the stable isotopic data record $\left(\delta^{18} \mathrm{O}\right.$ and $\delta \mathrm{D}$ ) is more continuous and longer. However, the deuterium values $(\delta \mathrm{D})$ were missing for the years 1970, 1971, 1972 and 1977. Accordingly, the monsoon meteoric water line (Fig. 2) was constructed using monthly values of $\delta^{18} \mathrm{O}$ and $\delta \mathrm{D}$ in summer (June to September) over the years 1961 to 1996 and the resulting linear relation is

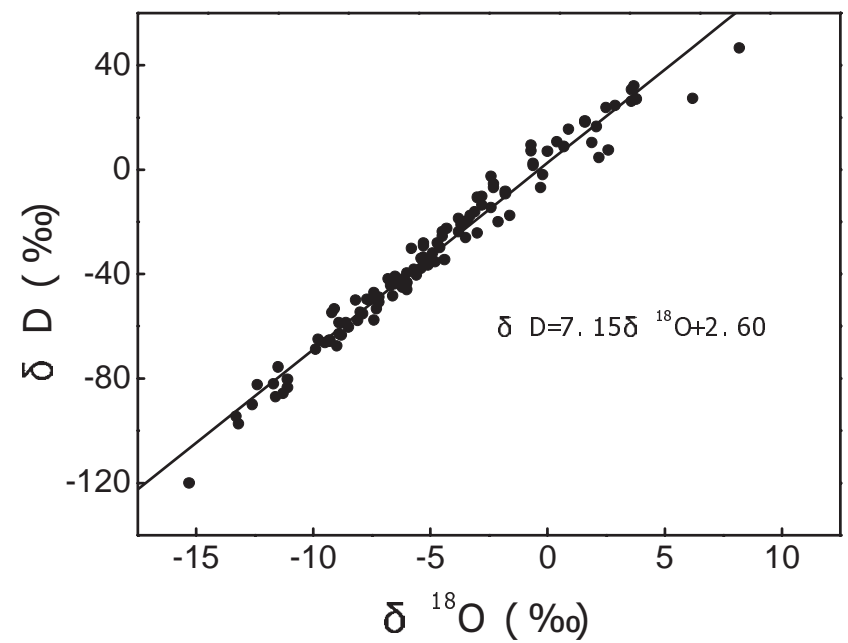

Fig 2. The meteoric water line in monsoon precipitation at New Delhi

$$
\delta \mathrm{D}=7.15 \delta^{18} \mathrm{O}+2.60 \text {. }
$$

Calculating the missing $\delta \mathrm{D}$ values from measured $\delta^{18} \mathrm{O}$ values for the four years using Eqn. (2), the deuterium excess series can be obtained according to Eqn. (1).

\section{Results}

To simplify the analysis, the Arabian Sea was divided into the western Arabian Sea $\left(10-20^{\circ} \mathrm{N}, 50-60^{\circ} \mathrm{E}\right)$, the eastern Arabian Sea $\left(10-20^{\circ} \mathrm{N}, 70-80^{\circ} \mathrm{E}\right)$ and the coastal sea off Somali $\left(0-10^{\circ} \mathrm{N}, 50-60^{\circ} \mathrm{E}\right)$; likewise, the South Indian Ocean was divided into the western South Indian Ocean $\left(30^{\circ} \mathrm{S}-0\right.$, $\left.40^{\circ} \mathrm{E}-60^{\circ} \mathrm{E}\right)$, the central South Indian Ocean $\left(30^{\circ} \mathrm{S}-0,60^{\circ} \mathrm{E}-\right.$ $\left.80^{\circ} \mathrm{E}\right)$ and the eastern South Indian Ocean $\left(30^{\circ} \mathrm{S}-0,80^{\circ} \mathrm{E}-\right.$ $\left.100^{\circ} \mathrm{E}\right)$. By re-analysing NCEP/NCAR data, the average values of summer relative humidity at the $1000 \mathrm{hPa}$ level were calculated for the six regions of the Indian Ocean. The only statistically-significant correlation with deuterium excess in monsoon rainfall at New Delhi was with the relative humidity of the Western Arabian Sea (Fig. 1). The curves in Fig. 3 are the cumulative anomalies of relative humidity and d-excess. The relative humidities may be divided into three stages: rising from 1961-1965 (Stage 1), falling from 1966-1984 (Stage 2) and rising 1985 to 1996 (Stage 3). Similarly, d-excess values decrease from 19611966 (Phase 1), increase from 1967-1984 (Phase 2) and decrease from 1985-1996. The manifestly negative correlation between the relative humidity and d-excess implies that the major vapour source of monsoon rain at New Delhi is in the western Arabian Sea.

From Fig. 3, it is obvious that two climatic discontinuities occurred in the mid-1960s and in the 1980s respectively; 

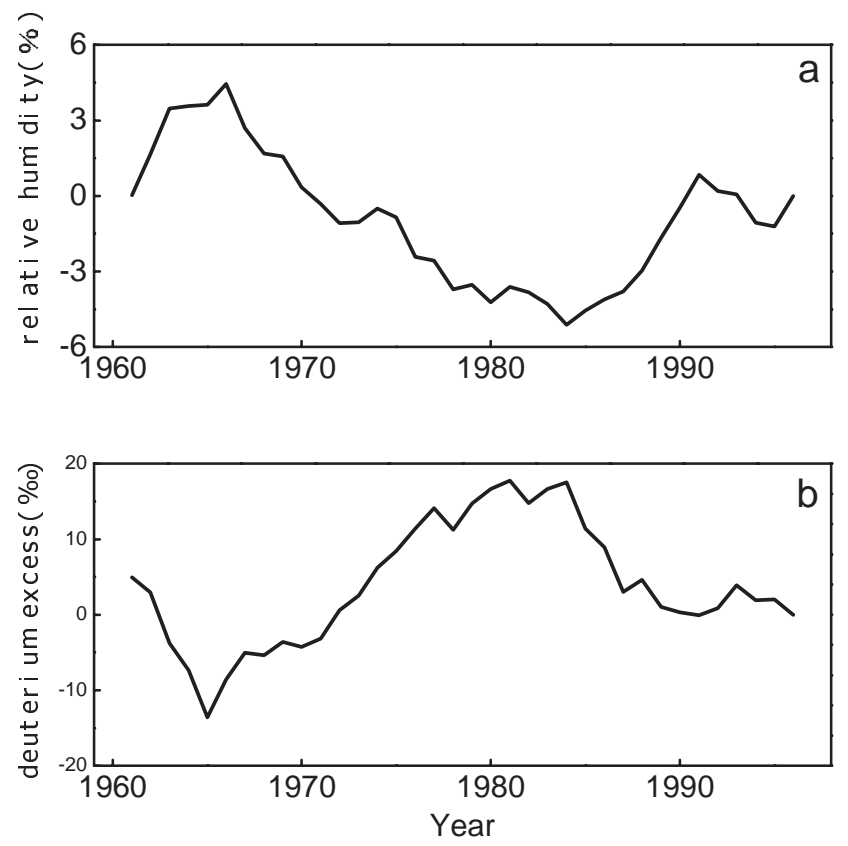

Fig 3. Cumulative anomalies from deuterium excess of monsoon precipitation at New Delhi and relative humidity at the $1000 \mathrm{hPa}$ level of the western Arabian Sea during 1961-1996

the former coincided with a change in the Asian Monsoon ( $\mathrm{Fu}$ and Fletcher, 1988) while the latter reflected a strengthening of the South Asian Monsoon in 1984 (Tang et al., 1998)

Figure 4 shows variations in the summer rainfall in northwestern India (the polygon in Fig. 1) as well as the average values of summer zonal wind speed and relative humidity above the western Arabian Sea at the $1000 \mathrm{hPa}$ level during 1961-1995. Statistical analyses indicate that the summer rainfall amount is positively correlated with the zonal wind speed, (correlation coefficient 0.71 significant at the $99 \%$ confidence level (Fig.4a, b)), suggesting that the zonal wind of the western Arabian Sea plays an important role in the summer rainfall in north-western India. Furthermore, the wind speed is negatively correlated with the relative humidity (correlation coefficient 0.45 at $99 \%$ confidence level) (Fig.4b, c), indicating that evaporation from the western Arabian Sea is transported eastward by the zonal wind. The stronger the wind, the more water vapour is transported, resulting in lower values of relative humidity and vice versa.

\section{Discussion and Summary}

Changes of the d-excess in precipitation at New Delhi recorded discontinuities in the South Asian Monsoon in the mid-1960s and mid-1980s, so variations in d-excess at New

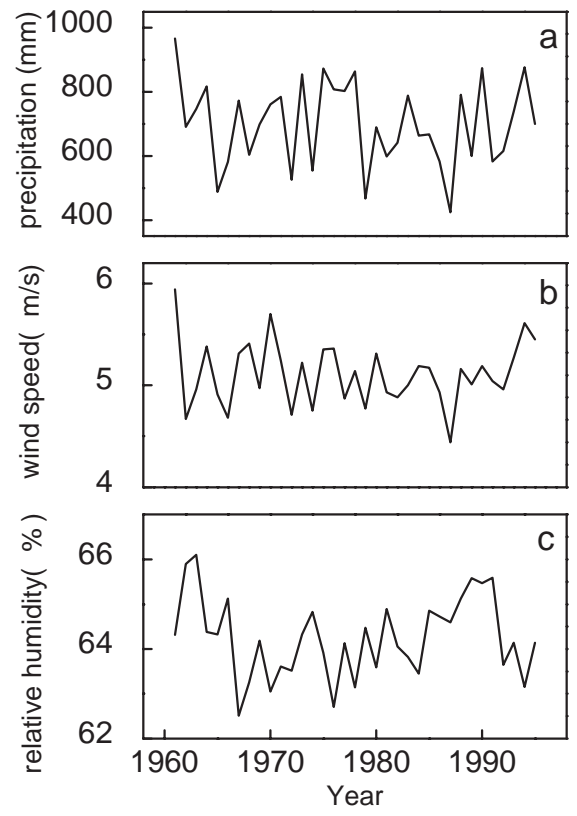

Fig 4. Variations of (a) the summer monsoon rainfall of northwestern India, (b) the zonal wind speed and (c) the relative humidity at the $1000 \mathrm{hPa}$ level over the western Arabian Sea

Delhi may be a typical proxy in monsoon behaviour. The correlation between the d-excess and the relative humidity above the western Arabian Sea suggests that monsoon precipitation at New Delhi is derived mainly from the western Arabian Sea. However, this conclusion cannot be extrapolated to the whole south-west monsoon region on the basis of d-excess data at a single station. Furthermore, this result is in conflict with the opinion that cross-Equatorial air flow is the main source of south-west monsoon precipitation.

The south-west monsoon is a large-complex climatic system which, during monsoonal seasons, behaves in different ways in different years, with active and more passive phases (Krishnamurthy and Shukla, 2000). Further work will clarify whether the vapour sources differ in the active and break phases or in the stronger and weaker monsoonal years, and whether the water vapour for precipitation in different parts of India is derived from the same sources.

\section{Acknowledgments}

The reported here was supported by the Hundred Talents Program(CAS2004-43) from Chinese Academy of Sciences, the funds of "Great Project for Western China Development"(90302006) and Outstanding Young Scientists(40121101) from the Chinese Natural Science 
Foundation, the Knowledge-Innovation Programme (210506) from LICCRE, Cold and Arid Regions Environmental and Engineering Institute, Chineses Academy of Sciences.

\section{References}

Craig, H., 1961. Isotopic variations in meteoric waters. Science, 133, 1702-1703.

Dansgaard, W., 1964. Stable isotopes in precipitation. Tellus, 16, 436-468.

Fu, C.B. and Fletcher, J., 1988. Large signals of climatic variation over the ocean in the Asian monsoon region. Adv. Atmos. Sci., 5, 389-404.

Jouzel, J. and Merlivat, L., 1984. Deuterium and oxygen-18 in precipitation: modeling of the isotope effects during snow formation. J. Geophys. Res., 89, 11749-11757.

Krishnamurthy, V. and Shukla, J., 2000. Intraseasonal and Interannual variability of rainfall over India. J. Climate, 13, 4366-4377.

Kumar, M.R. and Schluessel, P., 1988. Air-sea interaction over the Indian Ocean during the two contrasting monsoon years 1987 and 1988 studied with satellite data. Theor. Appl. Climatol., 60, 219-231.
Merlivat, L. and Jouzel, J., 1979. Global climate interpretation of the deuterium-oxygen 18 relationship for precipitation. $J$. Geophys. Res., 84, 5029-5033.

Murakami, T., Nakazowa, T. and He, T., 1984. On the 40-50 day oscillations during the monsoon during the northern hemispheric summer Part II:Heat and moisture budget. J. Meteorol. Soc. Japan, 62, 469-484.

Pearce, R.P. and Mohanty, U.C., 1984. Onsets of Asian summer monsoon, 1979-1982. J. Atmos. Sci., 41, 1620-1639.

Pisharoty, P.R., 1965. Evaporation from the Arabian Sea and the Indian southwest monsoon. Proc. Symp. Meteorological Results, IIOE, Bombay, India. 43-54.

Rao, G.V., Schaub Jr., W.R. and Puetz, J., 1981. Evaporation and precipitation over the Arabian Sea during several monsoon seasons. Mon. Weather Rev., 109, 364-370.

Sontakke, N.A. and Singh, N., 1996. Longest instrumental regional and all-India summer monsoon rainfall series using optimum observations: reconstruction and update. Holocene, 6, 315-331. Tang Maocang, Cheng Guodong and Lin Zhenyao, 1998. Contemporary Climatic Variations over Qinghai-Xizang (Tibetan) Plateau and Their Influences on Environments. Guangzhou: Guangdong Science \& Technology Press, Guangzhou (in Chinese). 